\title{
Sarcomatoid urothelial carcinoma with disseminated metastases: an aggressive and rare cancer
}

\author{
Babikir Kheiri, Abed Kanzy, Terry Krznarich, Ghassan Bachuwa
}

Internal Medicine, Hurley Medical Center, Flint, Michigan, USA

Correspondence to Dr Ghassan Bachuwa, gbachuw2@hurleymc.com

Accepted 8 September 2017

\section{DESCRIPTION}

A 48-year-old woman with medical history of chronic obstructive pulmonary disease (COPD), hypertension and chronic tobacco abuse. She presented to the emergency department with new-onset supraventricular tachycardia. She denied any urological symptoms. Physical examination revealed a cachectic woman but otherwise unremarkable. Her laboratory investigations showed hypercalcaemia at 1.58 (Ref: 1.1 to $1.3 \mathrm{mmol} / \mathrm{L}$ ) with low 25 -Hydroxy low vitamin D 25-Hydroxy at 5.6 at 5.6 (Ref: 30 to $100 \mathrm{ng} / \mathrm{mL})$, low parathyroid hormone level $<6.3$ (Ref: 14 to $72 \mathrm{pg} / \mathrm{mL}$ ) and elevated Parathyroid-related protein 83 (Ref: 14 to $27 \mathrm{pg} / \mathrm{mL}$ ).

She had a chest, abdomen and pelvis CT scan to rule out any underlining malignancy. The results revealed significant enhancement and nodular urinary bladder wall with intraluminal hyperdensities. In addition, there were innumerable small cavitating lung nodules scattered throughout the lung fields, hypodense lesion involving the right hepatic lobe, splenic nodule, disseminated lymphadenopathy, osseous diseases involving L4, L2, T8 and compression deformity with superior endplate fracture of L2 without retropulsion. Furthermore, multiple small foci of lytic disease were also seen in rest of the vertebral column, osseous pelvis, sacrum and iliac bones (figure 1).

The patient underwent cystoscopy which showed large bladder mass covering the anterior wall and the dome of the bladder. The mass was irregular and friable and measured more than $6 \times 6 \mathrm{~cm}$. She had transurethral resection of the bladder and the combined immunomorphological profiles were consistent with invasive carcinoma with extensive sarcomatoid differentiation (figures 2 and 3). The final diagnosis was likely disseminated metastases from a sarcomatoid urothelial carcinoma. Unfortunately, the patient died before further biopsies and treatment made.
A

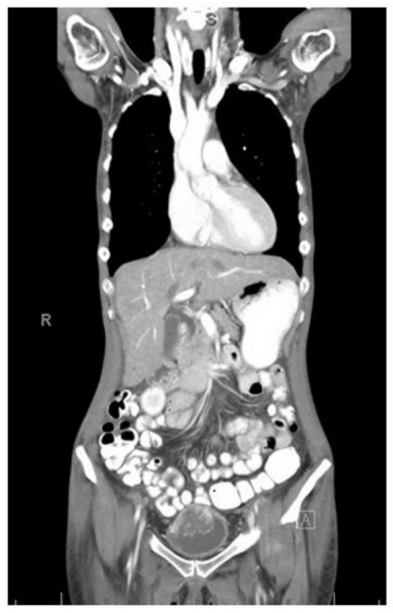

B

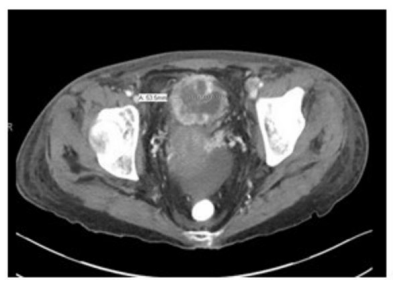

c

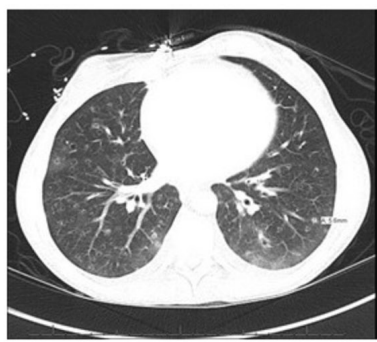

D

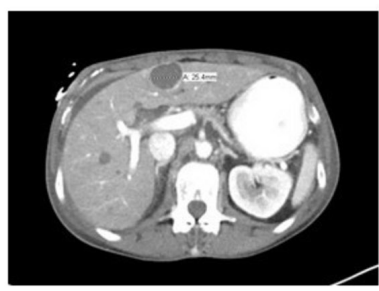

E

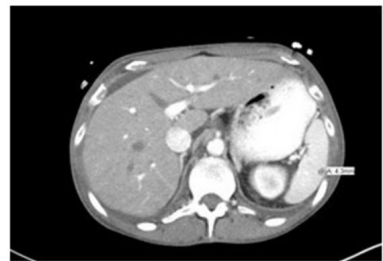

F

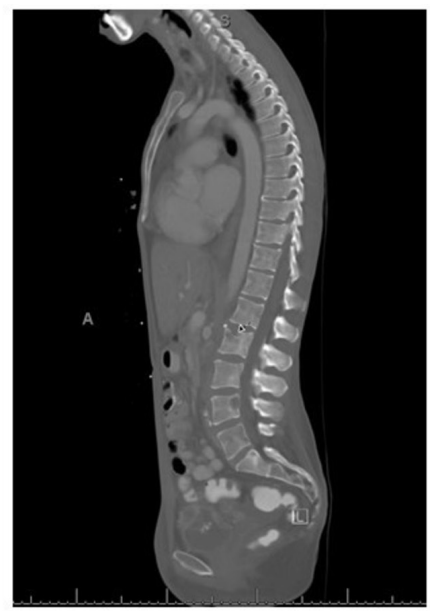

G

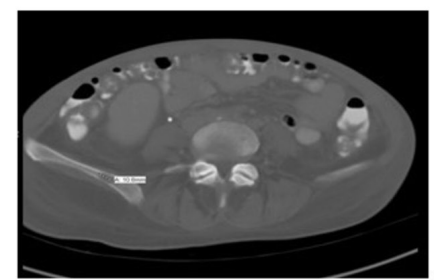

Figure 1 CT scans. (A) Coronal section showing the nodular urinary bladder wall with intraluminal hyperdensities. (B) Transverse section showing the nodular urinary bladder wall with intraluminal hyperdensities. (C) Transverse section showing innumerable small cavitating lung nodules scattered throughout the lung fields. (D) Transverse section showing hypodense lesion involving the right hepatic lobe. (E) Transverse section showing splenic nodule. (F) Sagittal section showing lytic lesions of the lumbar spine. (G) Transverse section showing iliac bones lytic lesions. 
A

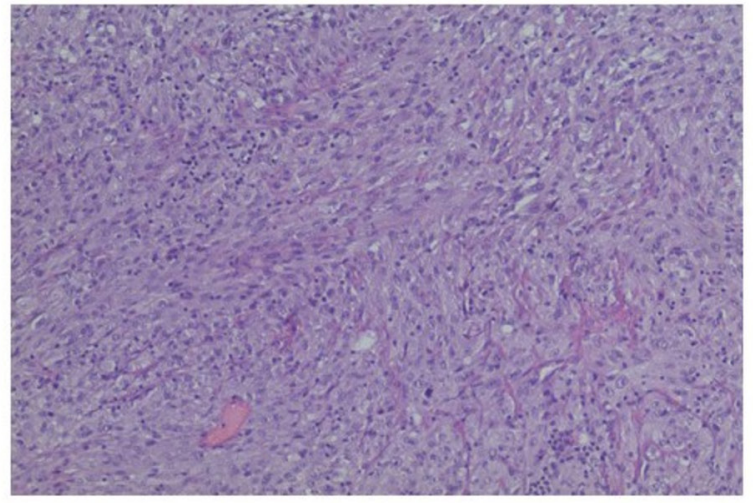

C

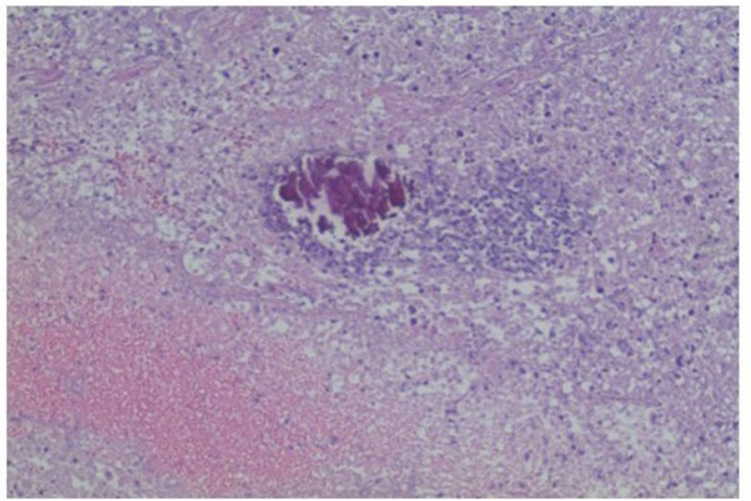

B

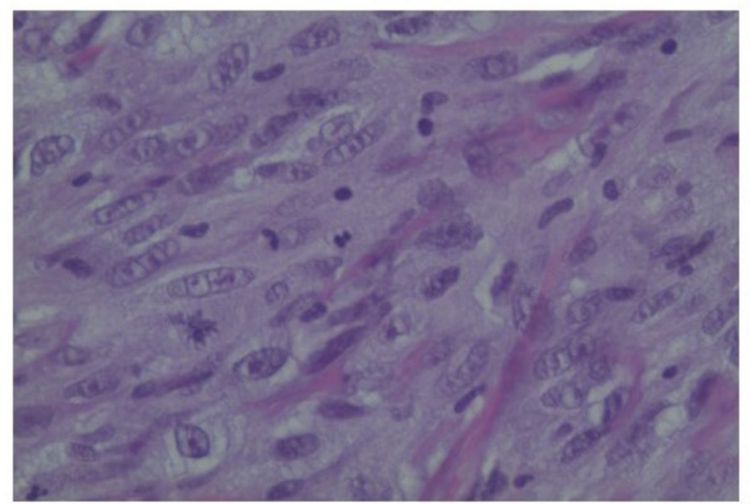

D

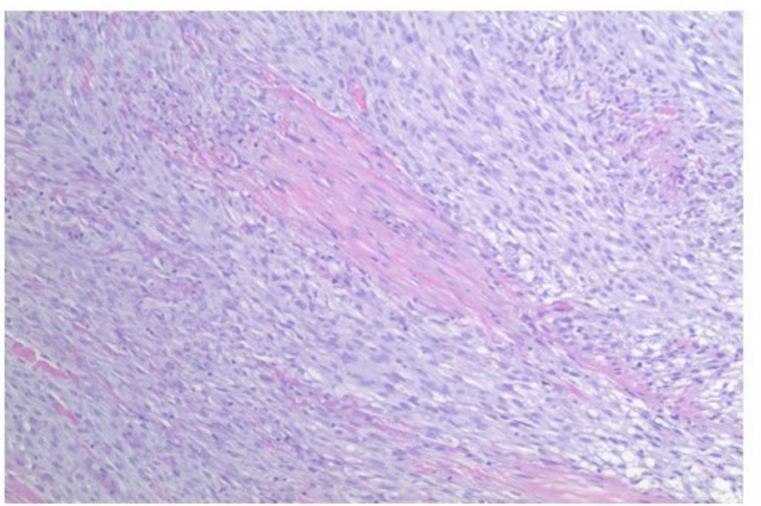

Figure 2 Morphological profile. (A) 10x H\&E-Malignant appearing spindle cells. (B) 40x H\&E-Spindle cells with severe nuclear atypia and mitotic figures. (C) 10x H\&E-Necrosis with calcification. (D) 10x H\&E-Tumour involving muscularis propria.

Sarcomatoid urothelial carcinoma is a rare and aggressive type of urothelial carcinoma with poor prognosis and usually associated with cigarette smoking. ${ }^{1}$ The tumour has both epithelial and mesenchymal components, hence previously termed carcinosarcoma. ${ }^{2}$ Therefore, the diagnosis requires a board panel of immunohistochemical stains to demonstrate both components which represent the process of epithelial-to-mesenchymal transition. ${ }^{2}$ There is
A

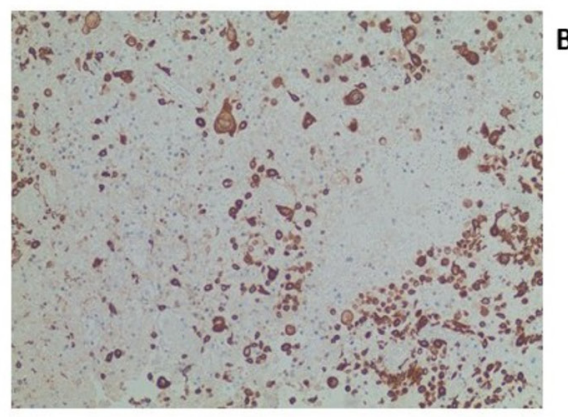

D

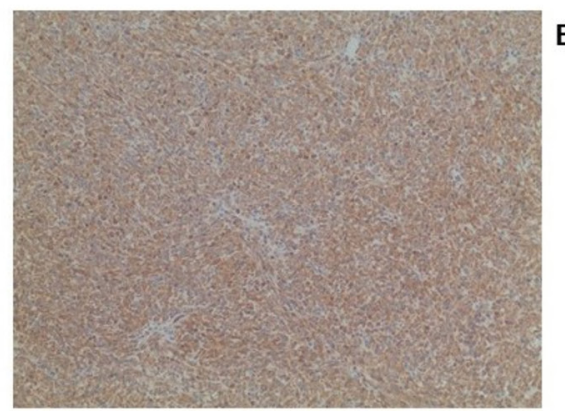

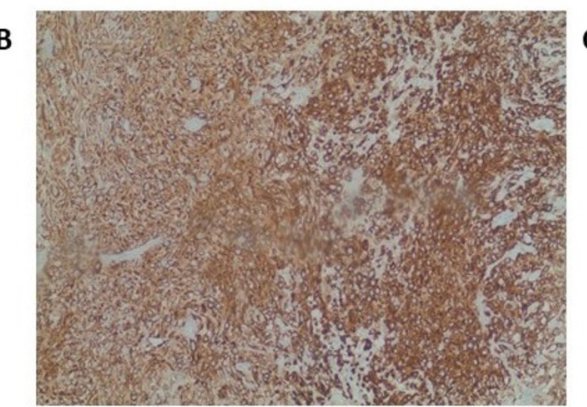

\section{C}
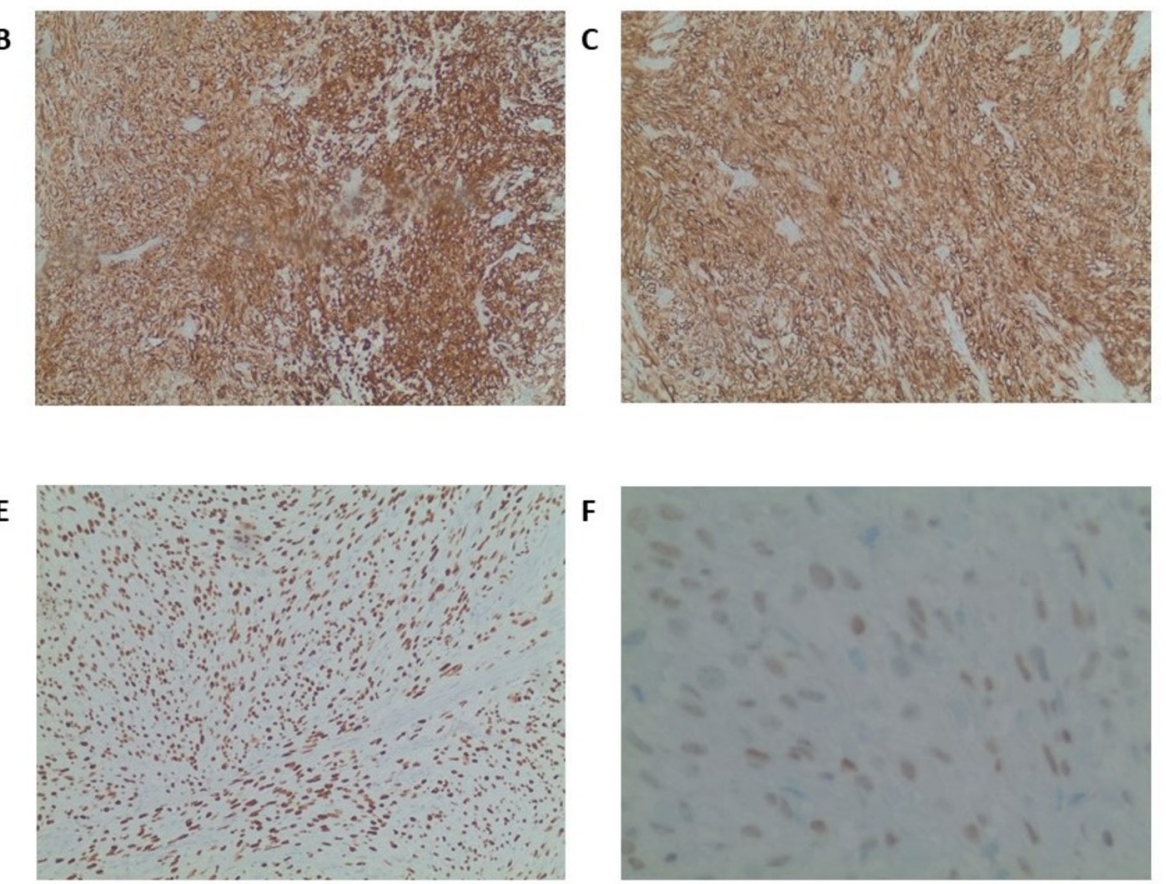

Figure 3 Immunohistochemical stains. (A) Positive for Cytokeratin AE1/AE3. (B) Positive for Cytokeratin 903. (C) Positive for Cytokeratin MNF116. (D) Positive for vimentin. (E) Positive for p63. (F) Positive for GATA3. 


\section{Learning points}

- Physician and pathologist should be aware of the aggressive sarcomatoid urothelial carcinoma as it carries a worse prognosis in comparison to the common urothelial carcinoma.

- Increased parathyroid-related protein and hypercalcaemia can be the first manifestation of sarcomatoid urothelial carcinoma.

- The diagnosis of sarcomatoid urothelial carcinoma requires demonstration of both epithelial and mesenchymal components using a variety of immunohistochemical stains.

still no standardised therapeutic protocol available because of the small reported cases and lack of clinical trials. ${ }^{3}$

Contributors BK planned, designed, wrote and critically revised the manuscript. In addition, he had an important role to facilitate the work between different authors.
He also did the literature review and images selection and preparation. AK did the literature review and he also wrote and revised the manuscript. TK and GB wrote and critically revised the manuscript. TK also participated in images and pathological description. GB also played a vital role in writing the learning points.

Competing interests None declared.

Patient consent Obtained.

Provenance and peer review Not commissioned; externally peer reviewed.

(c) BMJ Publishing Group Ltd (unless otherwise stated in the text of the article) 2017. All rights reserved. No commercial use is permitted unless otherwise expressly granted.

\section{REFERENCES}

1 Malla M, Wang JF, Trepeta R, et al. Sarcomatoid carcinoma of the urinary bladder. Clin Genitourin Cancer 2016;14:366-72.

2 Sanfrancesco J, McKenney JK, Leivo MZ, et al. Sarcomatoid urothelial carcinoma of the bladder: analysis of 28 cases with emphasis on clinicopathologic features and markers of epithelial-to-mesenchymal transition. Arch Pathol Lab Med 2016;140:543-51.

3 Molina-Cerrillo J, Martínez-Sáez 0, Alonso-Gordoa T, et al. Primary sarcomatoid tumor of the bladder: a different entity but the same approach? Clin Genitourin Cancer 2015;13:493-8

Copyright 2017 BMJ Publishing Group. All rights reserved. For permission to reuse any of this content visit

http://group.bmj.com/group/rights-licensing/permissions.

BMJ Case Report Fellows may re-use this article for personal use and teaching without any further permission.

Become a Fellow of BMJ Case Reports today and you can:

- Submit as many cases as you like

- Enjoy fast sympathetic peer review and rapid publication of accepted articles

- Access all the published articles

- Re-use any of the published material for personal use and teaching without further permission

For information on Institutional Fellowships contact consortiasales@bmjgroup.com

Visit casereports.bmj.com for more articles like this and to become a Fellow 